\title{
A Regulação do Mercado de Saúde e os Efeitos sobre a Seleção Adversa
}

\author{
André Nunes ${ }^{1}$ \\ Fernando Antônio Ribeiro Soares ${ }^{2}$ \\ Flávio Augusto Correa Basílio ${ }^{3}$
}

\begin{abstract}
Resumo: O objetivo do artigo é verificar se após a adoção do novo marco regulatório para as operadoras de saúde no Brasil, com a proibição da seleção adversa, proibição da rescisão unilateral dos contratos e das limitações de carências, houve melhoria de bem-estar para os consumidores dos planos de saúde. Verificou-se que, embora ocorra seleção adversa nos dois períodos considerados, verifica-se um agravamento do problema após o advento da regulação.
\end{abstract}

Palavras-Chave: Regulação em Saúde, Seleção Adversa.

Classificação JEL: I18.

\section{The Market Regulation and the Health Effects on Adverse Selection}

\begin{abstract}
1 Doutor em economia, professor da UnB. E-mail: andrenunes@unb.br.
2 Doutor em economia, professor da UCB. E-mail: fernando.soares@ucb.br.

3 Doutor em economia, professor da UDF. E-mail: flaviobasilio@gmail.com.
\end{abstract}

Abstract: The aim of this essay is to check if there has been improvement in the well-being of health insurance consumers after the adoption of a new regulatory mark which switched from a market of free enterprise action to a market of diverse controls and restrictions for health care providers, such as: prohibition of adverse selection, prohibition of unilateral contract annulment and limit setting. Although 
adverse selection occurred in the two analyzed periods, it has been surveyed that there was an aggravation in the latter year.

Key Words: Health regulation, adverse selection.

JEL Classification: $I 18$.

\section{Introdução}

O sistema de saúde brasileiro é pluralista em termos de formas organizacionais de atenção à saúde e das fontes de financiamento. Sua pluralidade se expressa nas quatro vias básicas de acesso da população aos serviços de saúde, que, segundo Ribeiro et al (2005), são: (a) Sistema Único de Saúde (SUS), de acesso universal, gratuito, financiado com recursos públicos; (b) Planos e seguros privados de saúde, de vinculação eletiva, financiado com recursos das famílias e/ou dos empregadores; (c) Planos e seguros destinados aos servidores públicos, civis e militares, de acesso restrito a essa clientela, financiado pelo empregador público e/ou pelos próprios servidores; (d) Provedores privados autônomos de saúde, de acesso direto mediante pagamento no ato (out-of-pocket).

Por motivos diversos, como qualidade do atendimento, tempo de espera, atendimento com médico de sua confiança e tecnologias avançadas, parcela significativa da população que pode pagar por uma assistência diferenciada prefere custear com recursos próprios suas demandas em saúde. Segundo a Agencia Nacional de Saúde (ANS), o ano de 2009 encerrou-se com o registro de 42,9 milhões de vínculos de beneficiários a planos de assistência médica. É sobre esse mercado que se debruça esse trabalho.

Caso o mercado de saúde suplementar funcionasse como uma economia competitiva, haveria poucas razões para regulação, entretanto como o mercado de saúde apresenta inúmeras imperfeições, justifica-se algum tipo de regulação. Há casos em que, mesmo em mercados competitivos, a regulação pode ser utilizada para melhorar o bem-estar do consumidor: demandas por universalização, proteção à saúde, competição destrutiva ou predatória.

O mercado das operadoras de saúde se transformou de mercado com livre atuação das empresas, para um mercado com diversos controles de funcionamento e restrições para as operadoras, como: proibição da seleção adversa, proibição da rescisão unilateral dos contratos e das limitações de carências. $\mathrm{O}$ marco regulatório atual, com a implementação do plano-referência, reduziu os tipos de contratos ofertados. A crítica que se coloca ao atual modelo é que a regulação deveria caminhar em sentido oposto, elevando a capilaridade da oferta de planos privados e observando os desejos dos consumidores. Desta 
forma, o consumidor poderia adquir um plano privado de cobertura mínima, para atender suas necessidades primárias de saúde, como consultas, exames e procedimentos ambulatoriais e poderia utilizar o SUS para procedimentos secundários e/ou terciários, por exemplo, internações. O arranjo inverso também é factível. O consumidor adquire um plano de saúde para situações de gastos catastróficos, ficando com a atenção primária e secundária sob a responsabilidade do SUS ou a cargo do próprio cidadão. Outra hipótese é que o plano cubra apenas a realização de exames de diagnóstico e/ou laboratoriais de difícil realização pelo SUS. Ou seja, em um marco regulatório que privilegiasse a capilaridade, um grande número de combinações, que proporcionem distintas coberturas de saúde, seria possível, inclusive a inserção de algum tipo de co-pagamento no SUS, respeitada as diferenças de renda. Tal modelo pode produzir melhoria no atendimento e no bem-estar do usuário, sem elevar os custos do sistema público. A regulação teria o caráter de controlar a qualidade e monitorar a prestação contínua e integrada do mix de serviços privados e públicos.

O objetivo específico do artigo é avaliar, empiricamente, se a implantação do plano referência, que obriga a operadora a oferecer cobertura ampla ao seu segurado não produz a seleção adversa.

\section{Questões relacionadas à seleção adversa no mercado de saúde}

A pergunta central a ser respondida nesse artigo é: a implementação do planoreferência ${ }^{1}$, que restringe a segmentação, produz uma melhoria no bem-estar dos consumidores? É interessante lembrar que ocorre seleção adversa quando a seguradora não consegue identificar os riscos associados aos segurados. Caso a seguradora consiga separar os segurados por seu nível de risco, revelando os custos para a seguradora, não ocorre a seleção adversa.

Seguradoras calculam os prêmios de acordo com os gastos esperados para cada indivíduo. Esse sistema de tarifação é denominado experience rating. Ele tem como conseqüência o pagamento de prêmios mais elevados por indivíduos de maior grau de risco, o que determina a exclusão de alguns grupos sociais do mercado de serviços de saúde. Duas formas usuais para se evitar a seleção adversa são as imposições de cláusulas sobre doenças preexistentes e tempo de carência para tratamentos específicos. Na tentativa de proteger os grupos sociais mais vulneráveis, a regulamentação produz algumas normas com o objetivo de evitar a discriminação. A regulação tenta induzir um rateio pela

\footnotetext{
1 Para obtenção do registro a operadora ficou obrigada a oferecer, a partir de 03/12/1999, um plano-referência a todos os atuais e futuros consumidores. O plano cobre, sem limitações, o atendimento ambulatorial e hospitalar do paciente. As operadoras podem oferecer apenas segmentos do plano-referência: plano ambulatorial, internação hospitalar, odontológico e obstétrico. Entretanto, dentro de cada segmento a cobertura deve ser completa. A lei impôs também restrições sobre a carência, mudanças de preços em função da idade e nas regras de inclusão de dependentes.
} 
média do risco dos compradores de planos e seguros de saúde, denominada community rating.

Caso a regulação permita ampla segmentação, as operadoras produzirão mecanismos de discriminação de usuários, excluindo-se os de mais alto risco, como os idosos, as mulheres em idade fértil, os portadores de doenças preexistentes e de doenças crônicas. Se a regulamentação não permitir a discriminação, somente os usuários de risco mais elevado aderem aos planos, pois o mecanismo de community rating eleva os preços, expulsando os usuários de baixo risco, como os indivíduos jovens e saudáveis do sexo masculino.

A agência reguladora brasileira, em busca da eqüidade entre os contratos, estipulou que as operadoras podem oferecer apenas segmentos do plano-referência, ou seja, plano ambulatorial, internação hospitalar, odontológico e obstétrico. Dentro de cada segmento a cobertura deve ser completa, não permitindo a exclusão de doenças preexistentes, porém, permitem-se tempos de carência, pois de outra forma indivíduos que vão precisar de algum serviço de saúde, poderiam entrar no plano para utilizar o serviço e sair logo em seguida, deixando o déficit para "sinquotização" entre os outros usuários. Exemplo comum desse comportamento são as internações para procedimentos obstétricos, como o parto cesariano ou normal. Na verdade, o que as operadoras desejam é reduzir a assimetria de informações, responsável pela distribuição desigual da informação entre produtores e consumidores. Em situação de informação simétrica, consumidores e produtores têm informação completa sobre preços, características e qualidade de qualquer bem ou serviço disponível nesse mercado. Consumidores serão tão bem informados sobre o produto quanto os produtores. Entretanto, no setor saúde, as informações são quase sempre assimétricas. A seguradora não possui a informação do 'tipo' do segurado e o segurado não tem informação completa sobre sua condição de saúde, tratamento disponível, resultados esperados e preços cobrados por outros prestadores vis-à-vis a qualidade do serviço prestado.

Para Andrade \& Lisboa (2001), a assimetria de informação gera problemas de seleção de risco, tais como seleção adversa e o cream skimming. No primeiro caso, os indivíduos que compõem o grupo de baixo risco saem da operadora, por não estarem dispostos a pagar mais do que o preço considerado justo, permanecendo os indivíduos de risco elevado, o que pode ter impacto negativo na estrutura de custos da empresa. O cream skimming ocorre em situação inversa. As operadoras conseguem segmentar o mercado e ofertar contratos diferenciados para consumidores com riscos distintos. Esses contratos são feitos de forma que o próprio indivíduo, ao escolher entre contratos diferenciados de seguro, revele seu grau de risco. A oferta de contratos não diferenciados, em geral, implica perda de bem-estar, os consumidores com risco mais baixo não poderiam desfrutar de cobertura plena, pois teriam de pagar o preço dos indivíduos de maior risco.

A principal questão da não segmentação e da criação do plano-referência 
reside em perguntar se alguns consumidores não podem preferir "melhor pacote" de serviços, pagando por ele preço mais elevado, enquanto outros estariam dispostos a ter certos atributos de qualidade reduzidos em face de custos mais baixos. Conhecer a qualidade e os preços, ou seja, as informações consistem no fator-chave para que haja competição efetiva.

Os contratos de planos de saúde especificam um conjunto de eventos médicos e serviços médico-assistenciais cujos custos são pagos pelas operadoras no caso da utilização dos mesmos. A maior parte dos contratos especifica também a rede provedora, na qual o beneficiário pode utilizar os serviços. No Brasil existem dois tipos básicos de contratos comercializados: os coletivos e os individuais. Os contratos coletivos são oferecidos a indivíduos que integram um grupo especifico de beneficiários, como no caso de plano coletivo oferecido por empresas privadas aos funcionários.

Dependendo da proporção de beneficiários de alto risco na população segurada e da extensão dos custos de contratação, o mercado competitivo de planos individuais de saúde pode ser instável (inexistência de equilíbrio) ou apresentar equilíbrio separador (Stiglitz \& Rothschild, 1976) ${ }^{2}$. Se o equilíbrio separador existe, os beneficiários de alto risco pagam elevado prêmio por um contrato de cobertura integral dos custos médico-assistenciais, enquanto os beneficiários de baixo risco pagam prêmio reduzido por uma cobertura parcial dos custos médico-assistenciais.

A separação dos contratos ofertados em equilíbrio decorre da existência de seleção adversa em um mercado, no qual as operadoras fixam livremente os prêmios e as coberturas dos contratos oferecidos. Essa alocação é Pareto-dominada pela primeira melhor alocação do mercado, associada à existência de informação simétrica entre as operadoras e os beneficiários sobre o tipo de risco de cada beneficiário. Na primeira melhor alocação todos os beneficiários adquirem contratos com cobertura integral dos custos médico-assistenciais e ambos pagam o prêmio igual a seu custo médico-assistencial esperado.

Crocker \& Snow (1985) mostraram que o conjunto de alocações Pareto-eficientes, denominadas de alocações de segunda melhor eficiência (second best efficient allocations), dominam, no sentido de Pareto, a alocação associada ao equilíbrio separador do mercado competitivo, sem intervenção regulatória ${ }^{3}$. Contudo, tais alocações não são alcançadas em um mercado competitivo, sem intervenção. Em equilíbrio, tais mercados não conseguem alcançar, simultaneamente, separação dos contratos ofertados para os beneficiários

2 Sobre equilíbrio separador ver também Wilson (1977), Schut (1995) e Newhouse (1996).

3 Mais precisamente, nas alocações de segunda melhor eficiência, os contratos satisfazem às seguintes condições: i) os beneficiários de alto risco adquirem contratos com cobertura integral dos custos médico-assistenciais; ii) os beneficiários de alto risco são indiferentes entre os seus contratos e os contratos adquiridos pelos beneficiários de baixo risco; e iii) as eventuais perdas (ou ganhos) nos contratos ofertados aos beneficiários de alto risco são completamente compensadas pelos ganhos (ou perdas) nos contratos ofertados aos beneficiários de baixo risco. As alocações de segunda melhor eficiência satisfazem às restrições de recursos e também às restrições informacionais de auto-seleção ou revelação da verdade: nenhum beneficiário deve obter benefício não revelando o seu verdadeiro tipo de risco (WARNICK, 2004). 
de diferentes tipos de risco e subsídio cruzado das perdas (ou ganhos) nos contratos oferecidos aos beneficiários de alto risco com os ganhos (ou perdas) nos contratos adquiridos pelos beneficiários de baixo risco. $\mathrm{Na}$ alocação de segunda melhor eficiência, o subsídio dos beneficiários de alto risco pelos beneficiários de baixo risco pode ser implementada em equilíbrio, pois a responsabilidade financeira assumida pelos beneficiários de baixo risco, pode ser compensada pela ampliação da cobertura dos custos médico-assistenciais. Portanto, existe amplo escopo para intervenções regulatórias, que objetivem o alcance de alocações de equilíbrio de segunda melhor eficiência (Warnick, 2004).

Nedeck \& Podczeck (1996) analisaram duas formas de intervenção regulatória. Na primeira, o regulador determina o oferecimento compulsório de contratos com cobertura parcial ou integral dos custos médico-assistenciais, especifica os prêmios e obriga as empresas privadas a aceitarem todos os beneficiários que desejarem tais contratos. Na segunda, o regulador especifica o nível mínimo de cobertura a ser oferecido, em qualquer contrato ofertado no mercado. A primeira forma de intervenção não gera alocação de segunda melhor eficiência e desestabiliza o mercado (inexistência de equilíbrio e bancarrota das empresas que não conseguem ofertar o contrato especificado). Portanto, a eficiência alocativa do equilíbrio separador, sem intervenção regulatória, não é ampliada. A segunda forma de intervenção gera um equilíbrio que não pertence ao loci de alocações de equilíbrio de segunda melhor eficiência.

O modelo de agente-principal é bastante utilizado para tratar questões de seleção adversa. Nesse modelo, o principal não possui toda a informação e o agente conhece perfeitamente as suas características. Na saúde suplementar, pode-se dizer que a seguradora faz o papel de principal, ela não conhece os riscos associados à venda do seguro, enquanto o segurado, ou agente, conhece o seu estado de saúde.

Arkerlof (1970) demonstrou que se todas as seguradoras do mercado não tiverem informação sobre os riscos associados ao produto que vendem, o mercado de seguros pode não existir, caso exista, será ineficiente. Para resolver esse problema, as seguradoras procuram discriminar os preços, associando o custo mais elevado ao segurado de maior risco (experience rating).

A forma usual de análise empírica de seleção adversa é através de uma base de dados que acompanhe os indivíduos ao longo do tempo, permitindo observar os efeitos de uma mudança na cobertura do seguro de saúde, de acordo com as características de risco. Cutler \& Zeckhauser (1997) analisaram a presença de seleção adversa, utilizando dados longitudinais da cobertura por seguro de saúde dos empregados da Universidade de Harvard. Os resultados apontaram a conveniência de mudança do sistema de subsídios generosos, para um sistema de divisão de pagamento igual do prêmio de seguro entre empregados e empregadores, o que resultou em significativa resposta por parte dos consumidores aos novos incentivos. Os empregados passaram a optar por 
planos menos generosos, o que gerou a queda substancial dos prêmios para esses tipos de planos, enquanto os planos mais generosos tiveram aumentos sucessivos em seus preços. Em três anos, os planos mais generosos deixaram de ser oferecidos nesse mercado, fato explicado pela seleção adversa nos planos de cobertura mais ampla, onde apenas segurados com taxa de risco mais elevada permanecem.

Sapelli \& Vial (2003) analisaram a presença de seleção adversa no sistema de saúde do Chile. A seleção é mensurada por característica de risco observável e não observável. O risco está associado à elevação da utilização do serviço de saúde, ou seja, a análise da seleção não observável é sinalizada por uma correlação positiva entre a probabilidade de ter plano e a utilização dos serviços de saúde. Os resultados, no modelo que considera a utilização de dias de internação como proxy de utilização, indicam a presença de seleção para atributos não observáveis contra as seguradoras para trabalhadores independentes e contra o seguro público para dependentes.

Mellor (2004), descreve inúmeras conseqüências da seleção adversa para consumidores e seguradoras de saúde e as soluções que podem ser implementadas pelo empregador em programas patrocinados pelo governo. Finkelstein \& McGarry (2003) demonstram que os mercados de seguro sofrem conseqüências negativas em termos de eficiência, causadas pela seleção adversa. Andrade \& Maia (2005) investigaram a presença de seleção adversa no sistema de saúde suplementar brasileiro. A base de dados foi a PNAD 98. Os principais resultados indicam que atributos de risco observáveis, como sexo e idade são importantes tanto na decisão de adquirir o plano de saúde, quanto na categoria do plano. As características de risco não observáveis não foram significativas.

Alves (2004) adapta o teste de seleção adversa de Chiappori e Salanié (2000) para estimar seleção adversa nos planos de saúde no Brasil. Na equação de probabilidade de escolha, o indivíduo opta entre adquirir um plano de saúde tipo amplo em contraposição a um tipo mínimo. A variável de utilização é construída por um índice que incorpora diferentes dimensões de utilização de serviços (internações, consultas, exames). Os resultados do teste indicam ausência de seleção adversa no mercado de saúde suplementar no Brasil.

Stiglitz \& Rothschild (1976) desenvolveram um modelo que propõe um mecanismo de auto-seleção, neste os indivíduos revelam as suas características quando escolhem os contratos oferecidos pela seguradora. A seguradora oferece amplo menu de contratos, com diferentes níveis de cobertura, com o objetivo de que os segurados revelem suas características. O indivíduo de risco mais elevado tende a escolher um contrato que dá direito a uma cobertura mais ampla. Esta forma de contratos se mostrou do ponto de vista da eficiência, superior àqueles que cobravam o preço médio. Outras informações adicionais, como idade, conhecimento do prontuário do segurado, seu histórico de vida, hábitos associados a riscos de saúde (fumante, sedentário) podem ser 
utilizadas como mecanismos reveladores do custo do segurado.

\section{O Modelo de Equilíbrio Competitivo de Stiglitz \&}

No caso do seguro saúde, a riqueza dos indivíduos pode ser dada por $W_{1}=W$ caso o indivíduo não tenha nenhuma enfermidade . Caso ocorra alguma enfermidade, sua riqueza fica diminuída dos custos associados à enfermidade (d). Então, sua riqueza será $W_{2}=W_{1}-d$. Caso o indivíduo compre um seguro-saúde, pagando um prêmio de $\alpha_{1}$, a seguradora se compromete, no caso de doença, a indenizá-lo como valor $\alpha^{\prime}{ }_{2}$. Então, a riqueza do indivíduo com o seguro será $W_{1}=W-\alpha_{1}$ e $W_{2}=W-\alpha_{1}+\alpha^{\prime}{ }_{2}-d$. Sabendo que $\alpha_{2}=\alpha_{2}^{\prime}-\alpha_{1}$, e que a probabilidade de ocorrência da doença é dada por $p$ pode-se dizer que o indivíduo maximiza suas preferências $(V()$.$) com$ relação a $\left(\left(\alpha_{1}, \alpha_{2}\right)\right)$ pela equação a seguir:

$$
V=\left(p, \alpha_{1}, \alpha_{2}\right)=(1-p) U\left(W-\alpha_{1}\right)+p U\left(W+\alpha_{2}-d\right)
$$

O modelo pressupõe que as seguradoras são neutras ao risco, que os indivíduos são avessos ao risco e que os segurados não alteram o seu comportamento após a compra do seguro de saúde (não existe perigo moral). O lucro da seguradora em um contrato vendido a um segurado com probabilidade $p$ é dado um par de $\left(\alpha_{1}, \alpha_{2}\right)$, tal que:

$$
\pi\left(p, \alpha_{1}, \alpha_{2}\right)=(1-p) \alpha_{1}-p\left(\alpha_{2}-\alpha_{1}\right)=(1-p) \alpha_{1}-p \alpha_{2}
$$

O conjunto de equilíbrio de contratos é definido como: i) os consumidores maximizando sua utilidade esperada; ii) nenhum contrato no equilíbrio pode ter lucro negativo, e; iii) nenhum contrato fora do equilíbrio, se oferecido, produz lucro positivo.

Há dois tipos de equilíbrio possíveis: o equilíbrio agregador (pooling) e o equilíbrio separador. No equilíbrio de pooling, ambos os grupos compram o mesmo contrato e $\left(1-p_{m}\right) \alpha_{1}-p_{m} \alpha_{2}=0$. No equilíbrio separador, cada grupo distinto compra contratos distintos. Então, os contratos adquiridos são: $\left(1-p_{a}\right) \alpha_{1}-p_{a} \alpha_{2}=0$, para o segurado 'a' e $\left(1-p_{b}\right) \alpha_{1}-p_{b} \alpha_{2}=0$ para o segurado 'b'. Stiglitz \& Rothschild (1976) mostram que o equilíbrio agregador é sempre superado por um contrato que forneça lucros positivos. Então, o único equilíbrio possível é o equilíbrio separador, no qual dois tipos 
de contratos são oferecidos (A e B), respectivamente, para os segurados de alto risco e de baixo risco. Quando os dois tipos de contratos são oferecidos, vale a condição de compatibilidade de incentivos e, então:

$$
V\left(p_{\alpha}, \alpha_{a}\right) \geq V\left(p_{\alpha}, \alpha_{b}\right) \text { e } V\left(p_{b}, \alpha_{b}\right) \geq V\left(p_{b}, \alpha_{a}\right)
$$

O agente de alto risco (a) comprará contratos completos e o agente de baixo risco (b) comprará contratos com menor nível de cobertura. A existência desse equilíbrio depende da proporcionalidade entre os agentes, caso fiquem no mercado apenas agentes de um único tipo, não haverá equilíbrio.

\section{Testando a Seleção Adversa pré e pós-Regulação}

Chiappori e Salanié (2000) elaboraram um teste para verificar a presença de seleção adversa, no mercado de seguro de automóveis na França. Alves (2004) aplicou o teste de Chiappori e Sanalié no mercado de seguros no Brasil, utilizando dados da PNAD de 1998. Nesse ensaio, utiliza-se o teste de Chiappori e Salanié, ex-ante e ex-post a implantação do plano-referência, com dados baseados na PNAD (suplemento de saúde) do ano de 1998 e de 2003.

Chiappori e Salanié (2000) identificaram as seguintes predições teóricas do modelo de equilíbrio competitivo desenvolvido por Stiglitz \& Rothschild (1976): (a) compradores e vendedores estão diante de amplo menu de contratos dentre o qual a escolha é livre; (b) os contratos de cobertura mais ampla possuem preços maiores que os de cobertura básica; (c) os compradores que têm maior probabilidade de utilização do seguro estão dispostos a comprar os contratos de cobertura mais ampla.

A suposição (a) é bastante abrangente, pois a escolha do contrato ótimo pelo agente depende não apenas do risco (ou custo do segurado), mas de outras características como: o nível de renda, as preferências (escolhas pessoais sobre um determinado médico) e da aversão ao risco do comprador. Identificar a parcela relativa às diferenças baseadas no risco requer a construção de outros pressupostos mais fortes. A predição da letra (b) demandaria o conhecimento prévio sobre as políticas de preços e da função de produção, como o conhecimento dos custos e da tecnologia empregada pelas seguradoras. Considerando as dificuldades inerentes a essas duas assertivas, opta-se por um teste que relacione a escolha dos contratos à sua probabilidade de utilização. Assim, não é necessário fazer hipóteses adicionais sobre a tecnologia adotada e as preferências dos consumidores (Alves, 2004).

O teste tem o objetivo de verificar a independência condicional entre a escolha dos contratos de cobertura ampla e a sua utilização. Sejam: $i=1, \ldots n$ os indivíduos; $X_{i}=$ vetor que representa o conjunto de variáveis exógenas 
para o individuo $i$.

Sejam as Variáveis Endógenas Dicotômicas: $y_{i}=1$ se $i$ compra o contrato com cobertura ampla (plano completo); $y_{i}=0$ se $i$ compra o contrato com cobertura mínima (plano simples); $z_{i}=1$ se $i$ tem alta utilização (elevado número de consultas ou internações); $z_{i}=0$ se $i$ não tem alta utilização (reduzido número de consultas ou internações).

Serão estimados dois modelos probits (binary probit), um para a escolha da cobertura e outro para utilização do contrato. Serão computados os resíduos das regressões: $\varepsilon_{i}$ e $\eta_{i}$.

Então, por exemplo, para $y_{i}$ teremos:

$$
\varepsilon_{\hat{i}}=E\left(\varepsilon_{i} / y_{i}\right)=\frac{\phi\left(X_{i} \beta\right)}{\Phi(X, \beta)} y_{i}-\left(1-y_{i}\right) \frac{\phi\left(X_{i} \beta\right)}{\Phi(X, \beta)},
$$

onde $\phi$ e $\Phi$ denotam a função de densidade e a função de distribuição acumulada da $N(0,1)$. Em seguida, seja a estatística $W^{4}$ definida como:

$$
W=\frac{\left(\sum_{n=1}^{n} \varepsilon_{\hat{i}} \eta_{\hat{i}}\right)^{2}}{\sum_{n=1}^{n} \varepsilon_{i}^{2} \eta_{i}^{2}}
$$

Gorieroux et al. (1987) mostraram que sob a hipótese nula da independência condicional, a $\operatorname{cov}\left(\varepsilon_{i}, \eta_{i}\right)=0$ e $W$ possui distribuição $\chi^{2}(1)$, ou seja, não há correlação entre os resíduos das duas probits. Esse é, então, o teste proposto por Chiappori e Salanié (2000): a rejeição da hipótese nula, de que os erros não estão correlacionados $(\operatorname{cov}=0)$ indica a presença de seleção adversa, ou seja, os erros são independentes. Em outras palavras, quando há probabilidade de $W$ ser zero é elevada há seleção adversa, quando $W$ é significativamente diferente de zero não podemos afirmar a presença de seleção adversa. Então: Ho: $\operatorname{cov}\left(\varepsilon_{i}, \eta_{i}\right)=0$, o que implica que os erros não estão correlacionados, portanto são independentes entre si, o que indica a presença de seleção adversa. $H a: \operatorname{cov}\left(\varepsilon_{i}, \eta_{i}\right) \neq 0$, o que implica que os erros são correlacionados, portanto são dependentes entre si, o que indica a ausência de seleção adversa. Por exemplo, para um W de 0,25, com distribuição $\chi^{2}(1)$, o valor limite tabelado é 3,84, com 95\% de probabilidade de ocorrência, o que indica que

4 A estatística W original do modelo de Chiappori e Salanie é $W=\left(\sum_{n=1}^{n} w_{i} \varepsilon_{i} \eta_{i}\right)^{2} / \sum_{n=1}^{n} w_{i}^{2} \varepsilon_{i}^{2} \eta_{i}^{2}$, onde w representa o peso do número de dias ano cobertos pelo seguro. No modelo aqui apresentado, o peso não foi considerado, pois as perguntas utilizadas da PNAD não possibilitam a captura dessa variável. 
não se pode rejeitar Ho (a hipótese da independência), ou seja, de ocorrência da seleção adversa.

A aplicação desse arcabouço no mercado de seguros de saúde exige algumas adaptações. A base de dados que suporta a análise é a Pesquisa Nacional por Amostra de Domicílio (PNAD/1998 e PNAD/2003). Nesses dois anos, foram incluídas informações de saúde nas PNADs -o suplemento de saúde-, o que possibilitou a análise do setor de saúde suplementar. A metodologia de construção do modelo, similar ao proposto por Alves (2004), está descrita em três etapas: a construção da variável de escolha; a construção da variável de utilização e a criação das variáveis exógenas.

Decididas qual a variável de escolha $(E)$, ela foi definida da seguinte forma: $E=1$, se o indivíduo possui um contrato do tipo completo, seguro amplo; e $E=0$, se o indivíduo possui um contrato simples ou seguro mínimo.

O tipo de plano é a proxy da escolha do cliente, que se divide em duas categorias, os planos simples e os completos. Os planos completos são aqueles que permitem reembolso de pagamento a médicos, hospitais, laboratórios ou outros serviços credenciados ou dão direito a medicamentos fora de internação, além das demais coberturas dos planos simples. Os planos simples são definidos por exclusão.

Na prática, fez-se uma combinação de duas perguntas da PNAD sobre cobertura do plano de saúde, para definir se os segurados possuem cobertura de planos definidos como completos ou simples. Para cada observação da PNAD, com resposta positiva à pergunta "tem direito a algum plano de saúde particular" combinada com a "o titular é quem paga a mensalidade", ou seja, tem plano de saúde custeado com recurso próprio, o modelo probit separa-as em planos simples ou completos.

O próximo passo foi à construção da variável de utilização. No modelo original a variável utilização é trivial, associada à utilização ou não do seguro do automóvel (ocorreu ou não o sinistro). No caso do seguro saúde, a mera utilização do seguro não é uma boa resposta, pois um segurado que utilizou seu seguro para realizar uma consulta preventiva (um check-up) não pode ser considerado como um segurado de risco. O trabalho constitui em criar uma proxy que represente um grau elevado ou não de utilização do plano. Para tal foram utilizados dois modelos. O primeiro modelo utiliza-se das internações como proxy de consumo e o segundo faz das consultas a proxy de consumo em saúde.

O terceiro passo é a criação das variáveis exógenas de controle, sendo selecionadas cinco variáveis: a renda (log_renda), anos de estudo (log_estudo), idade (log_idade), morador ou não de região metropolitana e sexo. As primeiras três variáveis são contínuas e as duas últimas discretas e dicotômicas.

Os resultados dos testes de seleção adversa (teste W - Tabela 1) mostraram- 
-se muito sensíveis ao que se define como número de internações utilizadas para estipular o quanto seria uma utilização elevada em saúde. Quando se utiliza uma internação para definir um elevado consumo em saúde, o modelo mostra aderência com as hipóteses teóricas, pois não há ocorrência de seleção adversa em 1998 e, após a regulação, em 2003, ela passa a aparecer. Entretanto, para qualquer proxy que considere um número maior do que uma internação, nos dois períodos considerados, não se pode rejeitar a presença de seleção adversa. Uma possível explicação seria a de que até uma internação, em 1998, havia alguma previsibilidade por parte do consumidor do plano e, sendo assim, ele comprava o plano completo quando previa a ocorrência de até uma internação, fato até razoável, pois a previsão de um número mais elevado é bastante improvável.

Ao fazer das internações a proxy do modelo de utilização, os resultados dos testes de W e da probabilidade do valor conter o zero, ou seja a $\operatorname{cov}\left(\varepsilon_{i}, \eta_{i}\right)=0$, que implica a ocorrência de seleção adversa, podem ser observados na Tabela 1.

TABELA 1: ESTATÍSTICAS DE W E PROBABILIDADE QUIQUADRADO PARA O MODELO DE UTILIZAÇÃO DE INTERNAÇÕES, PNADS 1998 E 2003

\begin{tabular}{lcccc}
\hline $\begin{array}{l}\text { Quantidade de } \\
\text { Internações }\end{array}$ & $\begin{array}{c}\text { W para } \\
\mathbf{1 9 9 8}\end{array}$ & $\begin{array}{c}\text { Prob W } \\
\mathbf{( 1 9 9 8 )}\end{array}$ & $\begin{array}{c}\text { W para } \\
\mathbf{2 0 0 3}\end{array}$ & $\begin{array}{c}\text { Prob W } \\
(\mathbf{2 0 0 3 )}\end{array}$ \\
\hline 1 & 9,3878 & 0,0021 & 1,0209 & 0,3122 \\
2 & 2,4101 & 0,1205 & 2,8352 & 0,0922 \\
3 & 0,2661 & 0,6059 & 0,0001 & 0,9899 \\
4 & 0,0325 & 0,8568 & 0,0092 & 0,9235 \\
5 & 1,2868 & 0,2566 & 0,0746 & 0,7846 \\
6 & 1,0612 & 0,3029 & 0,0956 & 0,7571 \\
7 & 1,0612 & 0,3029 & 0,0488 & 0,8250 \\
8 & 0,1508 & 0,6977 & 0,0488 & 0,8250 \\
9 & 0,1265 & 0,7219 & 0,0488 & 0,8250 \\
\hline
\end{tabular}

Fonte: elaboração do autor.

Os resultados apontam para não existência de seleção adversa, no ano de 1998, apenas quando a proxy considera a ocorrência de uma internação. Para todos os demais valores de W, com distribuição $\chi^{2}(1)$, com 95\% de probabilidade de ocorrência, não se pode rejeitar Ho (a hipótese da independência), ou seja, não se pode rejeitar a ocorrência da seleção adversa nos dois períodos, para o número de internações variando entre duas e nove internações.

Verifica-se que, a partir de três internações realizadas, os valores de W, para o ano de 2003, são estatisticamente muito diferentes de zero, o que pode ratificar a sugestão de uma exacerbação da seleção adversa após a implantação da regulação. 
Os resultados da Tabela 2, modelo que tem as consultas como proxy de utilização, apontam para a não existência de seleção adversa em dois períodos analisados, em 1998, para 10 consultas, e, em 2003, para 5 consultas. Nos demais modelos testados, não se pode afirmar que $\operatorname{cov}\left(\varepsilon_{i}, \eta_{i}\right) \neq 0$, ou seja, que não ocorre seleção adversa.

Entretanto, em 1998, para um número igual ou superior a sete consultas, quando se afrouxa o nível de significância dos testes de W, com distribuição $\chi^{2}(1)$, para 90\%, não se pode rejeitar Ha (a hipótese da dependência), ou seja, não se pode rejeitar a ausência da seleção adversa. A questão passa a ser a identificação de um padrão de consumo de consultas que possa ser considerado elevado.

TABELA 2: ESTATÍSTICAS DE W E PROBABILIDADE QUIQUADRADO PARA O MODELO DE UTILIZAÇÃO DE CONSULTAS, PNADS 1998 E 2003

\begin{tabular}{lcccc}
\hline $\begin{array}{l}\text { Quantidade de } \\
\text { Internações }\end{array}$ & $\begin{array}{c}\text { W para } \\
\mathbf{1 9 9 8}\end{array}$ & $\begin{array}{c}\text { Prob W } \\
\text { (1998) }\end{array}$ & $\begin{array}{c}\text { W para } \\
\mathbf{2 0 0 3}\end{array}$ & $\begin{array}{c}\text { Prob W } \\
\text { (2oo3) }\end{array}$ \\
\hline 1 & 0,7274 & 0,3937 & 0,3252 & 0,5684 \\
2 & 0,0172 & 0,8954 & 0,5478 & 0,4591 \\
3 & 1,3600 & 0,2435 & 1,8548 & 0,1732 \\
4 & 0,4699 & 0,4929 & 2,0735 & 0,1498 \\
5 & 1,0620 & 0,3027 & 4,4766 & 0,0343 \\
6 & 2,1342 & 0,1440 & 2,7941 & 0,0946 \\
7 & 2,7815 & 0,0953 & 1,8647 & 0,1720 \\
8 & 2,8453 & 0,0916 & 1,6763 & 0,1954 \\
9 & 2,3614 & 0,1243 & 2,2366 & 0,1347 \\
10 & 4,6652 & 0,0307 & 0,7985 & 0,3715 \\
\hline
\end{tabular}

Fonte: elaboração do autor.

Valendo-se das estatísticas descritivas, pode-se encontrar uma proxy de consumo elevado de consultas. Para o ano de 1998, a moda para as consultas é 1, a mediana é 2, a média é de 4,79. Para o ano de 2003, modifica-se apenas a média que é de 4,90. Então, considerando o padrão médio de, aproximadamente, cinco consultas por ano, pode-se dizer que sete consultas é um consumo "exagerado" desse procedimento. Associando-se sete consultas a consumo exagerado, observa-se que, para esse número ou mais, há também um agravamento da seleção adversa para o ano de 2003, quando comparado com o ano de 1989, repetindo o padrão de exacerbação da seleção adversa pós-regulação, observado no modelo de internações.

Uma possível interpretação, para que o modelo que considera sete consultas um consumo exagerado, indique a ausência de seleção adversa, é que os com- 
pradores de planos de saúde que "consomem muito" (sete ou mais consultas), possuíam razoável expectativa a respeito do número de consultas que iriam realizar e, assim, em 1998, optavam por um plano completo. Entretanto, com o advento da regulação, houve um agravamento da seleção adversa e as seguradoras têm, em 2003, mais dificuldades para vender planos completos aos consumidores que mais utilizam o que eleva o risco no mercado de saúde suplementar.

\section{Considerações Finais}

Na intenção de proteger os grupos mais vulneráveis, o regulador implantou o modelo do plano referência, que impõe uma redução do menu de contratos, pois garante que, dentro de cada segmento de plano a cobertura seja completa. Com essa nova estrutura, as seguradoras passam a induzir um rateio pela média do risco dos compradores elevando o preço médio para todos os segurados. O problema dessa solução é que os indivíduos de baixo risco podem não querer pagar o novo prêmio de seguro, saindo do mercado. Se isso ocorrer, ficam no mercado apenas os de mais alto risco, o que produz impactos na estrutura de custos da seguradora, o que eleva os preços para o novo número de segurados, mais reduzido.

Utilizando os dados da PNAD/ suplemento saúde de 1998 e 2003 realizou-se o teste de Chiappori \& Salanié para seleção adversa. Os resultados, sensíveis ao modelo de utilização empregado, apontam para existência de seleção adversa, em quase todo o período analisado. Ao empregar o modelo de internações como proxy de utilização, observa-se que para o ano de 1998, com emprego de uma internação como proxy de utilização, não há evidências de seleção adversa. Para os demais modelos, que se utilizam de um número maior de internações, não se pode afirmar a ausência de seleção adversa, parecendo haver uma exacerbação do problema em 2003. Finalmente, o modelo que traz as consultas como proxy de utilização, aponta também para existência de seleção adversa em ambos os períodos. Não obstante, quando se considera um número igual ou superior a sete consultas e se relaxa o nível de significância para 90\%, o modelo indica um agravamento da seleção adversa no período pós-regulação.

\section{Referências}

Alves, S. L. (2004). Estimando Seleção Adversa em Planos de Saúde. In Economia: Selecta do XXXII Encontro Nacional de Economia da ANPEC. João Pessoa, PB.

Andrade, M.V. \& Lisboa, M.B. (2001). Economia da Saúde no Brasil. In Microeconomia e Sociedade no Brasil (Lisboa, M. \& Menezes F. N., orgs.), p. 285-331, Rio de Janeiro: FGV/RJ. 
Andrade, M.V; Maia A.C. (2005). A Seleção Adversa no Sistema de Saúde Suplementar Brasileiro. Relatório final de projeto: estudos em métodos quantitativos aplicados a defesa da concorrência e a regulação econômica. SDE/IPEA/ ANPEC: Brasília.

ANS (2010). Cadastro de Beneficiários e Operadoras da ANS/MS. Acessível em:<http://www.ans.gov.br/portal/site/consultas/consultas.asp >.

Chiappori, P. A. (2000). Econometric models of insurance under asymmetric information. Handbook of Insurance, pages 365-393.

Chiappori, P. A. \& Salanié, B. (2000). Testing for assimetric information in insurance markets. Journal of Political Economy, 108:56-78.

Crocker, J. A. K.; Snow, A. (1985). A simple tax structure for competitive equilibrium and redistribution in Insurance Markets with Asymmetric Information. Journal of Public Economics, n. 26, p. 207-219.

Cutler, D., Zeckhauser, R. (1997). Adverse selection in health insurance. NBR working paper (working paper 6107). Cambrigde MA.

Finkelstein, A; Mcgarry, K. (2003). Private information and its effect on market equilibrium: New evidence from long-term care insurance. National Bureau of Economic Research (NBER). Working paper, n. 9957, Massachusetts.

Gourieroux C. \& Monfort A. \& Renault E. (1987). Consistent m-estimators in a semi-parametric model. CEPREMAP Working Papers (Couverture Orange) 8720, CEPREMAP.

Mellor, J. M. (2005). Illustrating adverse selection in health insurance markets with a classroom game. Department of Economics, College of Willian and Mary. Working paper, n. 11. Williansburg.

Nedeck, W.; Podczeck, K. (1996). Adverse selection and regulation in health insurance markets. Journal of Health Economics, n. 15, p. 387-408.

Sapelli, C. \& Vial, B. (2003). Self-selection and moral hazard in Chilean health insurance. Journal of Health Economics 830. p.1-18.

Stiglitz, J. E.; Rothschild, M. (1976). Equilibrium in competitive insurance markets: as essay in the economics of imperfect information. Quarterly Journal of Economics, n. 90, v. 4, p. 629-649.

Warnick, T. S. (2004). Seleção adversa, ajustamento ótimo de risco e regulação dos contratos individuais de planos de saúde. IPEA. Prêmio em Economia da Saúde. Mimeo. 